\title{
BMJ Open Health and financial burden of adverse childhood experiences in England and Wales: a combined primary data study of five surveys
}

\author{
Karen Hughes (D , , ${ }^{1,2}$ Kat Ford, ${ }^{3}$ Rajendra Kadel, ${ }^{1}$ Catherine A Sharp, ${ }^{3}$ \\ Mark A Bellis ${ }^{1,2}$
}

To cite: Hughes K, Ford K, Kadel $\mathrm{R}$, et al. Health and financial burden of adverse childhood experiences in England and Wales: a combined primary data study of five surveys. BMJ Open 2020;10:e036374. doi:10.1136/ bmjopen-2019-036374

- Prepublication history and additional material for this paper are available online. To view these files, please visit the journal online (http://dx.doi org/10.1136/bmjopen-2019036374).

Received 12 December 2019 Revised 11 February 2020 Accepted 12 May 2020

Check for updates

(C) Author(s) (or their employer(s)) 2020. Re-use permitted under CC BY-NC. No commercial re-use. See rights and permissions. Published by BMJ.

${ }^{1} 1$ World Health Organization Collaborating Centre on Investment for Health and Wellbeing, Policy and International Health, Public Health Wales, Wrexham, UK

${ }^{2}$ School of Human Sciences, Bangor University, Wrexham, UK

${ }^{3}$ Public Health Collaborating Unit, College of Human

Sciences, Bangor University, Wrexham, UK

Correspondence to

Prof Karen Hughes;

k.e.hughes@bangor.ac.uk

\section{ABSTRACT}

Objective To estimate the health and financial burden of adverse childhood experiences (ACEs) in England and Wales.

Design The study combined data from five randomly stratified cross-sectional ACE studies. Population attributable fractions (PAFs) were calculated for major health risks and causes of ill health and applied to disability adjusted life years (DALYs), with financial costs estimated using a modified human capital method.

Setting Households in England and Wales.

Participants 15285 residents aged 18-69.

Outcome measures The outcome measures were PAFs

for single (1 ACE) and multiple (2-3 and $\geq 4$ ACEs) ACE exposure categories for four health risks (smoking, alcohol use, drug use, high body mass index) and nine causes of ill health (cancer, type 2 diabetes, heart disease, respiratory disease, stroke, violence, anxiety, depression, other mental illness); and annual estimated DALYs and financial costs attributable to ACEs.

Results Cumulative relationships were found between ACEs and risks of all outcomes. For health risks, PAFs for ACEs were highest for drug use (Wales 58.8\%, England $52.6 \%$ ), although ACE-attributable smoking had the highest estimated costs (England and Wales, £7.8billion). For causes of ill health, PAFs for ACEs were highest for violence (Wales 48.9\%, England $43.4 \%$ ) and mental illness (ranging from $29.1 \%$ for anxiety in England to $49.7 \%$ for other mental illness in Wales). The greatest ACE-attributable costs were for mental illness (anxiety, depression and other mental illness; England and Wales, £11.2 billion) and cancer (£7.9 billion). Across all outcomes, the total annual ACE-attributable cost was estimated at $£ 42.8$ billion. The majority of costs related to exposures to multiple rather than a single ACE (ranging from $71.9 \%$ for high body mass index to $98.3 \%$ for cancer). Conclusions ACEs impose a substantial societal burden in England and Wales. Policies and practices that prevent ACEs, build resilience and develop trauma-informed services are needed to reduce burden of disease and avoidable service use and financial costs across health and other sectors.

\section{INTRODUCTION}

Evidence linking adverse childhood experiences (ACEs) to the adoption of health risk
Strengths and limitations of this study

- Adverse childhood experiences (ACEs) are known to increase individuals' risks of poor health across the life course, yet the financial burden they impose on national economies is largely unmeasured.

- We combined primary data on ACEs and 13 health outcomes from five general population ACE surveys undertaken in England and Wales.

- For each outcome, we generated population attributable fractions for cumulative ACE exposure and applied these to disability adjusted life years, which in turn allowed calculation of financial burden of ACEs using a modified human capital approach.

- ACE data were retrospectively reported and may be affected by recall bias, while general household surveys by their nature are likely to exclude those that have suffered the greatest impact of ACEs (eg, homelessness, incarceration or premature death).

- Although many major health outcomes were included in the study, data are not yet available on all health outcomes potentially associated with ACEs and financial estimates are likely to be conservative.

behaviours and the development of mental and physical illness has burgeoned in recent years. ${ }^{1}$ The term ACEs is used to describe some of the most intense sources of stress that children can suffer while growing up, such as being maltreated, witnessing domestic violence or coping with parental substance abuse. ${ }^{2}$ Such experiences can have harmful effects on children's developing neurological and physiological systems that can embed vulnerability to poor health and well-being. Thus repeated activation of the stress response system during childhood and a lack of responsive interaction with caring adults can impact on brain structure, neuroendocrine stress regulation, immune functioning and metabolic health, as well as social and emotional development. ${ }^{34}$ Consistent with such effects, ACEs 
have been associated with delayed child development (eg, cognitive and language skills), childhood health and behavioural conditions, the adoption of health risk behaviours (eg, substance use), mental illness (eg, depression), and early development of chronic health conditions (eg, cancer). ${ }^{15-8}$

Numerous studies have explored the health impacts and costs of specific ACEs such as child maltreatment. ${ }^{9-11}$ However, the ACE framework provides a mechanism for measuring a range of ACE types and the cumulative risks they impose at a population level. ${ }^{2}$ Studies using this approach show a dose-response relationship between the number of ACEs suffered and poor outcomes across multiple domains, including health, criminal justice, education and employment. ${ }^{12-15}$ Studies also show that most individuals who report having suffered any specific ACE type (eg, physical abuse) also report other ACE types. ${ }^{16}$ Consequently, prevention efforts focused on any individual ACE type are likely to have limited success if the range of other ACEs affecting families are left unaddressed. The rapid proliferation of awareness on the impacts of ACEs on the policy priorities of different sectors is driving multiagency action to enhance early intervention and develop trauma-informed services. ${ }^{1718}$ However, such policy development requires an understanding of the financial costs of ACEs to society and consequently the potential gains to be made by preventing ACEs for future generations.

Estimates of the financial burden of ACEs are only just starting to emerge. A recent study estimated that the annual costs attributable to ACEs for four risk factors (smoking, alcohol use, drug use and obesity) and six causes of ill health (anxiety, depression, cancer, diabetes, cardiovascular disease and stroke) reached $\$ 581$ billion in Europe and $\$ 748$ billion in North America, equivalent to around 3\% of each region's gross domestic product (GDP). ${ }^{12}$ Here, we combine primary data from five ACE studies undertaken in England and Wales to develop national population attributable fractions (PAFs) for ACEs across an extended range of outcomes. We use these data to estimate the annual cost of the health burden resulting from the lifelong impact of ACEs on residents of England and Wales using a modified human capital model.

\section{METHODS}

\section{Primary data sources}

We combined data from five cross-sectional ACE studies conducted across various geographies in England and Wales between 2012 and 2017..$^{19-23}$ Summary information on each study is provided in online supplementary table S1. All studies used stratified random sampling approaches with lower super output area (LSOA; small geographical areas with a mean population of 1500) as the sampling unit. LSOAs were categorised into deprivation quintiles based on their ranking in the English ${ }^{24}$ or Welsh $^{25}$ Indexes of Multiple Deprivation, both of which are composite measures including a range of economic and social indicators. Sample selection was stratified by region (as appropriate; see online supplementary table S1) then deprivation quintile based on the population profile of the relevant study area. Households in sampled areas were identified using the national postcode address file. In four studies, randomly selected households were sent a letter prior to researcher visits that provided information on the study and the opportunity to opt out. In one study, ${ }^{22}$ researchers randomly selected households in sampled LSOAs and provided study information materials at the door. Interviews were undertaken face to face at participants' homes by professional market research companies using computer-assisted personal interviewing. Informed consent was obtained from all participants. Sensitive questions, including those on ACEs, were selfcompleted. Participation was voluntary and anonymous and only one resident participated per selected household (inclusion criteria: within age range, resident in the LSOA, cognitively able to participate in a face-to-face interview). Across the five samples, the weighted average compliance was $55.7 \%$ (see online supplementary table S1), with a total sample size of 15658 . For this study, data were restricted to individuals aged 18-69 with complete demographic and ACE data, resulting in a final sample of 15285 .

All questionnaires used the Centers for Disease Control and Prevention short ACE tool ${ }^{26}$ to collect data on nine ACEs occurring before the age of 18: physical abuse, sexual abuse, verbal abuse, parental separation, exposure to domestic violence, and household member alcohol abuse, drug abuse, mental illness and incarceration. For the purpose of analysis, and in line with previous studies, ${ }^{19-23}$ positive responses to ACE questions were summed and participants were allocated to an ACE count category: 0 ACE, 1 ACE, 2-3 ACEs and $\geq 4$ ACEs. Questions used to determine ACEs and the 13 health outcomes analysed in this study are shown in online supplementary table S2. All studies provided data on smoking (current smoker), drug use (ever used heroin or crack cocaine) and violence (victimisation in the past year). Four studies provided data on alcohol use (current, $\geq 12 \mathrm{~g}$ per day), high body mass index (BMI, $\geq 25.0 \mathrm{~kg} / \mathrm{m}^{2}$ ), and whether respondents had ever been diagnosed with cancer, type 2 diabetes, heart disease (coronary heart disease/heart attack), stroke or respiratory disease. One study provided data on whether respondents had ever been treated for depression, anxiety and other mental illness (see online supplementary table S3). Demographic variables included gender, age, ethnicity (self-assigned using UK census categories) and deprivation quintile.

\section{Calculating PAFs}

Statistical analysis was undertaken in SPSS V.23, with data editing and calculations undertaken in Excel. Binomial generalised linear modelling was used to calculate risk ratios (RRs) and 95\% CIs associated with ACE count level for each health outcome, controlling 
Table 1 Risk ratios for risk factors and causes of ill health at each ACE count level

\begin{tabular}{|c|c|c|c|c|c|c|c|c|c|}
\hline & \multicolumn{3}{|c|}{1 ACE } & \multicolumn{3}{|c|}{ 2-3 ACEs } & \multicolumn{3}{|c|}{$\geq 4$ ACEs } \\
\hline & RR & $95 \% \mathrm{Cl}$ & $P$ value & RR & $95 \% \mathrm{Cl}$ & $P$ value & RR & $95 \% \mathrm{Cl}$ & P value \\
\hline \multicolumn{10}{|l|}{ Risk factors } \\
\hline Smoking & 1.188 & 1.091 to 1.293 & $<0.001$ & 1.448 & 1.329 to 1.578 & $<0.001$ & 2.079 & 1.904 to 2.270 & $<0.001$ \\
\hline Drug use & 1.648 & 1.168 to 2.327 & 0.005 & 3.184 & 2.342 to 4.330 & $<0.001$ & 8.685 & 6.658 to 11.328 & $<0.001$ \\
\hline \multicolumn{10}{|l|}{ Causes of ill health } \\
\hline Depression & 1.560 & 1.305 to 1.865 & $<0.001$ & 2.137 & 1.820 to 2.509 & $<0.001$ & 2.766 & 2.374 to 3.223 & $<0.001$ \\
\hline Anxiety & 1.429 & 1.169 to 1.747 & $<0.001$ & 2.151 & 1.806 to 2.563 & $<0.001$ & 2.751 & 2.316 to 3.266 & $<0.001$ \\
\hline Other mental illness & 1.684 & 1.008 to 2.812 & 0.046 & 3.216 & 2.083 to 4.964 & $<0.001$ & 5.115 & 3.356 to 7.796 & $<0.001$ \\
\hline Violence & 1.383 & 1.107 to 1.728 & 0.004 & 2.955 & 2.448 to 3.566 & $<0.001$ & 5.625 & 4.745 to 6.667 & $<0.001$ \\
\hline Stroke & 1.238 & 0.800 to 1.918 & 0.338 & 1.427 & 0.906 to 2.250 & 0.125 & 2.705 & 1.660 to 4.409 & $<0.001$ \\
\hline Respiratory disease & 1.224 & 0.927 to 1.615 & 0.155 & 1.806 & 1.383 to 2.358 & $<0.001$ & 2.612 & 1.929 to 3.536 & $<0.001$ \\
\hline
\end{tabular}

Analysis used generalised linear modelling controlling for study sampling region, deprivation quintile, age, gender and ethnicity. Reference category: 0 ACE.

ACE, adverse childhood experience; BMI, body mass index; Cl, confidence interval; RR, risk ratio.

for study sampling region, deprivation quintile of residence, gender, age and ethnicity (white or non-white). In line with cost estimates for global regions, ${ }^{12}$ we calculated PAF values at each ACE count level (1 ACE vs 0 ACEs; 2-3 ACEs vs 0 ACE ; $\geq 4$ ACEs vs 0 ACE) according to the following:

$$
\mathrm{PAF}_{\mathrm{ACE} \alpha}=\frac{\mathrm{P}_{\mathrm{ACE} \alpha} \mathrm{x}\left(\mathrm{RR}_{\mathrm{ACE} \alpha}-1\right)}{\left(\mathrm{P}_{\mathrm{ACE}}\right)+\left(\mathrm{P}_{\mathrm{ACE} 1} \times \mathrm{xR}_{\mathrm{ACE} 1}\right)+\left(\mathrm{P}_{\mathrm{ACE} 2}-3 \times \mathrm{RR}_{\mathrm{ACE2} 2-3)+\left(\mathrm{P}_{\mathrm{ACE} 4+} \times \mathrm{xR}_{\mathrm{ACE} 4+}\right)}\right.}
$$

where ${ }_{\alpha}$ is the category of ACE count for the PAF in question, $\mathrm{RR}_{\mathrm{ACE}}$ is the pooled $\mathrm{RR}$ associated with each ACE count, and $\mathrm{P}_{\mathrm{ACE}}$ is the proportion of the sample exposed to each ACE count. Overall PAFs for ACEs were generated by summing the three PAF values. ${ }^{27}$ Separate PAFs were generated for England and Wales using regional ACE prevalence levels.

\section{Calculating ACE-attributable costs}

Consistent with previous studies, ${ }^{11} 1228$ we used a modified human capital approach to calculate ACE-attributable costs associated with each health outcome. The human capital approach is a commonly used method in economic evaluations to calculate the cost of lost productivity to society as a result of separation of an individual from the labour force due to premature death or morbidity. ${ }^{29}$ Health outcomes were matched to risk factor and cause categories in the 2017 Global Burden of Disease Study ${ }^{30}$ (GBD; see online supplementary table S4). For each matched category, disability adjusted life years (DALY) estimates were extracted for England and Wales for age categories $15-49$ years, 50-69 years and 70+ years. Previous cost estimates using a human capital approach have assumed one DALY is equal to a region's GDP per capita and calculated costs based on DALYs $\times$ GDP per capita. ${ }^{11228}$ GDP was not calculated separately for England and Wales; thus, we used the related measure of regional gross value added (GVA; equivalent to GDP plus subsidies less taxes on products), with GVA per capita (balanced, current basic 2017 prices) being £28 096 for England and $£ 19899$ for Wales. ${ }^{31}$ PAFs were applied to the total cost (by UK region) for each risk factor and cause to estimate the economic value of DALYs by ACE level. The equivalent value of DALYs as a proportion of total GVA was also calculated. To estimate the total costs attributed to ACEs across all health outcomes studied, we excluded DALYs for risk factors that related to included causes of ill health (eg, those for alcohol use attributed to cancer). Sensitivity analyses were run limiting DALYs to individuals aged 15-69years old, using the upper and lower bounds (uncertainty intervals) for DALYs (extracted from the GBD) and by generating PAFs using the upper and lower CIs for RRs.

\section{Patient and public involvement}

Patients and the public were not involved in the design or planning of the study.

\section{RESULTS}

Demographics and ACE count levels of the individual and combined study samples are shown in online supplementary table S5. Across the combined samples, over half (54.9\%) of participants were female and $85.7 \%$ were of white ethnicity. ACE prevalence levels (used to generate PAFs) were $53.1 \%$ for 0 ACE, $19.0 \%$ for $1 \mathrm{ACE}, 15.2 \%$ for 


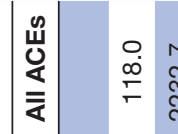

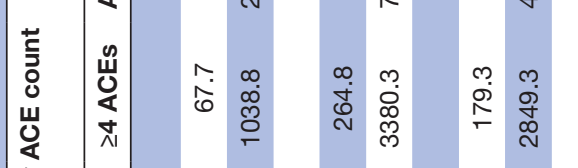

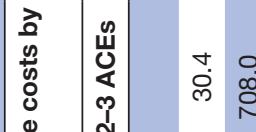

帚 흘

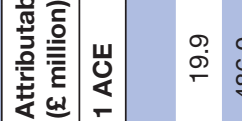

范

8

है

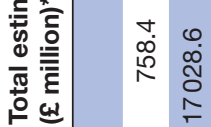

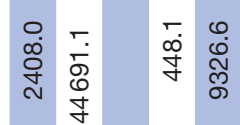

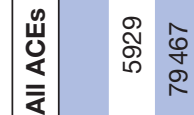

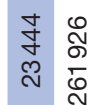

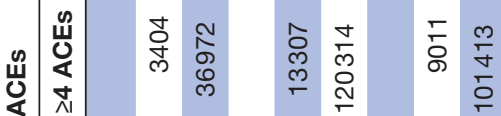

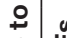

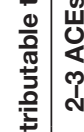

$\pi$

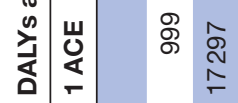

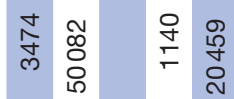

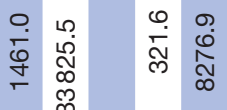

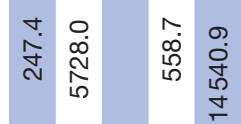

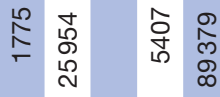

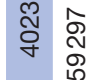

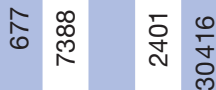

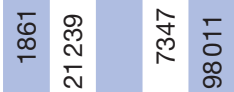

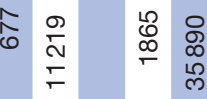

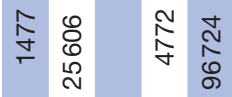

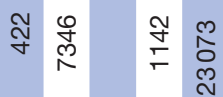

范

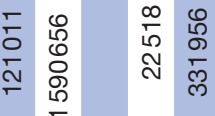

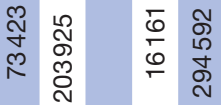

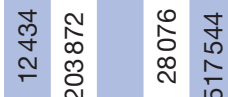

旁

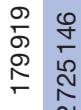

స్ ్․

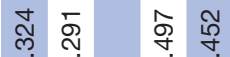

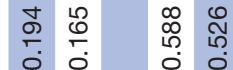

$\begin{array}{llll}\circ & 0 & 0 & 0 \\ ㄷ & 0 & 0 & 0 \\ 0 & 0 & 0 & 0 \\ 0 & 0 & 0\end{array}$

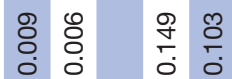

윧유 뭄

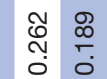

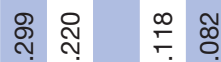

㞼

लํ 용

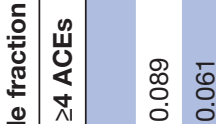

○

岂

$\frac{0}{\frac{0}{0}}$

焉

옹 ำ

员

웅 웅 눋 중

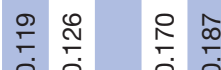

단 온

$\stackrel{0}{0}$

$\begin{array}{llll}0 & 0 & 5 & \infty \\ 0 & 0 & 0 & 0 \\ 0 & 0 & 0 & 0\end{array}$

)

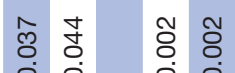

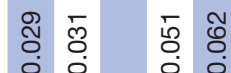

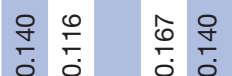

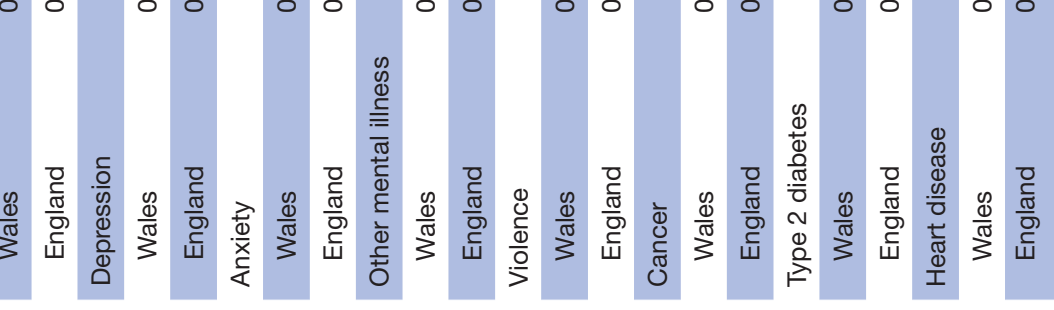

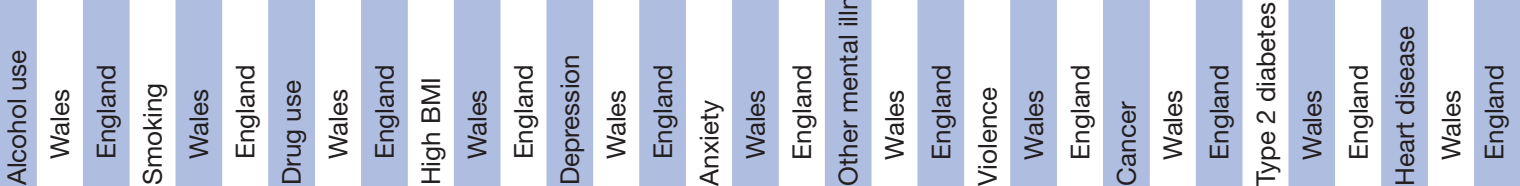


2-3 ACEs and $12.6 \%$ for $\geq 4$ ACEs in Welsh samples, and $56.2 \%$ for 0 ACE, $20.1 \%$ for 1 ACE, $15.4 \%$ for 2-3 ACEs and $8.4 \%$ for $\geq 4$ ACEs in English samples.

RRs for each ACE count level and each health outcome are presented in table 1 (unadjusted proportions are provided in online supplementary table S6). All outcomes showed a graded relationship with ACEs, with RRs increasing as ACE count increased. Risks of alcohol use, smoking, drug use, violence and mental illness outcomes were increased in individuals with any level of ACEs. Risks of high BMI, heart disease and respiratory disease were increased in individuals with $\geq 2$ ACEs, and risks of type 2 diabetes, cancer and stroke in those with $\geq 4$ ACEs only.

The total PAFs for ACEs were slightly higher in Wales than in England for all outcomes due to higher ACE prevalence levels (table 2). Across the four risk factors, drug use had the highest PAFs due to ACEs (58.8\% Wales, $52.6 \%$ England). However, smoking carried the highest ACE-attributable costs given the higher number of DALYs for this risk factor. ACE-attributable costs due to smoking were $£ 7.4$ billion in England and $£ 466.5$ million in Wales. High BMI had the lowest PAFs due to ACEs (2.4\% Wales, 2.2\% England), although ACE-attributable costs still reached £729.2 million in England and £35.3 million in Wales. Across causes of ill health, violence and mental illness had the highest PAFs due to ACEs, while cancer and type 2 diabetes had the lowest. ACEs were attributed to $48.9 \%$ of recent violence victimisation in Wales and $43.4 \%$ in England, with associated costs of $£ 16.6$ million and £355.0 million, respectively. Up to a third of depression and anxiety and almost half of other mental illnesses were attributed to ACEs, with associated costs across the three mental health outcomes being $£ 465.3$ million in Wales and £10.7billion in England. Despite having low PAFs, high DALYs for cancer meant that this cause carried the greatest ACE-attributable costs across all individual outcomes measured, reaching $£ 476.4$ million in Wales and $£ 7.5$ billion in England.

Across all nine causes of ill health, the total ACEattributable cost was $£ 33.9$ billion ( $£ 1.7$ billion for Wales and $£ 32.1$ billion for England). To calculate the total ACE-attributable cost across all risk factors and causes of ill health, we excluded DALYs from the four risk factors that related to included causes (eg, those for smoking related to cancer). The total ACE-attributable cost was $£ 42.8$ billion ( $£ 2.2$ billion for Wales and £40.6billion for England; table 3). These costs are equivalent to $3.5 \%$ of the total annual GVA in Wales and 2.6\% in England (2.6\% across the combined geographies). In sensitivity analysis (see the Methods section), combined estimated ACEattributable costs for England and Wales ranged from $£ 16.3$ billion (equivalent to $1.0 \%$ of GVA) to £68.4 billion (4.2\% of GVA; table 3 ).

Figure 1 shows the proportion of ACE-attributable costs for each outcome that were accounted for by 1, 2-3 and $\geq 4$ ACEs. For cancer, the 1 ACE category accounted for only $1.7 \%$ of ACE-attributable financial costs, while the $\geq 4$ ACEs category accounted for $84.2 \%$. For other outcomes, 


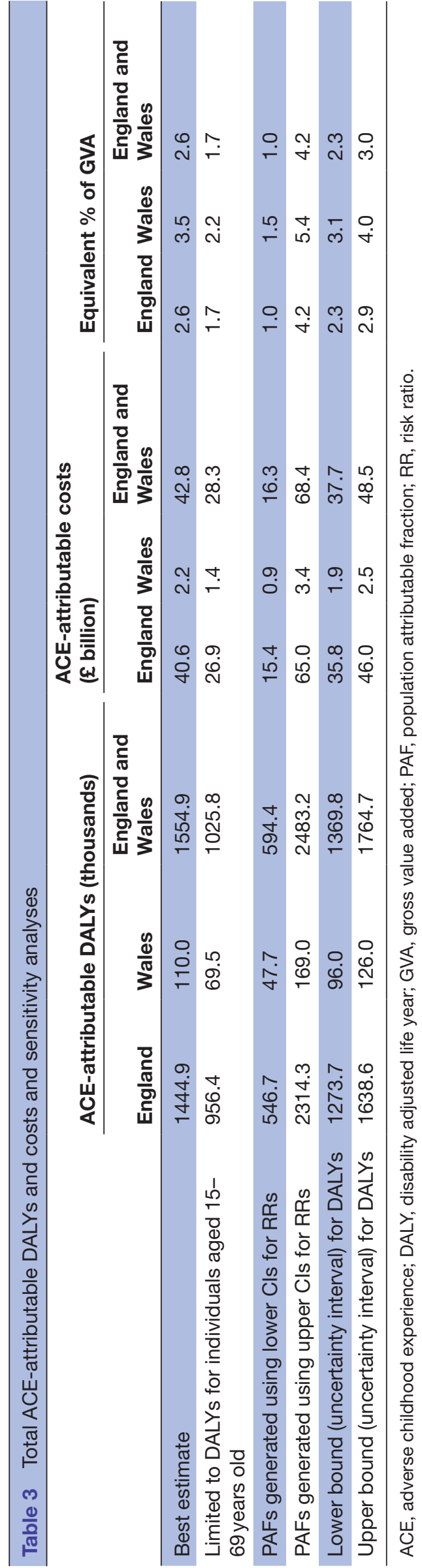

the proportion of costs accounted for by the 1 ACE category ranged from $9.9 \%$ (violence) to $28.1 \%$ (high BMI), while the proportion accounted for by $\geq 4$ ACEs ranged from $28.9 \%$ (high BMI) to $58.6 \%$ (drug use).

\section{DISCUSSION}

In this study of 15285 adults in England and Wales, we found a dose-response relationship between ACEs and all outcomes measured. Violence, mental illness and drug use had the highest PAFs due to ACEs, while mental illness, cancer and smoking carried the highest ACE-attributable costs. Across all outcomes studied, the total estimated annual ACE-attributable cost across England and Wales was $£ 42.8$ billion, equivalent to $2.6 \%$ of the total GVA in England and Wales and representing approximately $£ 1800$ per household per annum. ${ }^{32}$ The majority of these costs related to multiple ACE categories.

\section{Comparison with other studies}

There are no previous studies estimating the costs of ACEs in England and Wales. However, a study that generated PAFs for ACEs through meta-analyses of risk estimates in published literature estimated the annual costs of ACEs to be equivalent to $2.7 \%$ of GDP in Europe and $3.6 \%$ of GDP in North America. ${ }^{12}$ Other studies have measured the costs of specific ACEs, particularly violence against children, using similar human capital approaches. Such costs have been estimated to be equivalent to between $1.2 \%$ and $3.5 \%$ of subregional GDP in East Asia and the Pacific $^{11}$; to $4.3 \%$ of GDP in South Africa ${ }^{33}$; and to $0.8 \%$ of GDP for physical abuse, $0.5 \%$ for emotional abuse and $0.4 \%$ for sexual abuse in China. ${ }^{34}$ In the UK, the lifetime cost per victim of non-fatal child maltreatment by a primary caregiver has conservatively been estimated at $£ 90000 .{ }^{35}$ However, this estimate excluded costs for several outcomes considered in our study, including those for cancer, type 2 diabetes and heart disease, due to no association being found between these conditions and the study's single measure of child maltreatment. We found no associations between such conditions and the single ACE category, yet strong associations with multiple ACEs. Thus $98.3 \%$ of the ACE-attributable costs of cancer, $87.6 \%$ of those for heart disease and $76.3 \%$ of those for type 2 diabetes were accounted for by suffering more than one type of ACE.

\section{Strengths and weaknesses of the study}

We used an established methodology ${ }^{11} 1228$ and based our approach on that used to estimate the financial burden of ACEs across Europe and North America. ${ }^{12}$ An acknowledged limitation of this previous study was the lack of consistency in study methodologies. Key strengths of the current study are the use of primary data and consistency in study methodologies, with all studies using representative household samples and the same set of questions to measure ACEs. However not all outcomes were measured in all studies, and mental illness was only measured in 


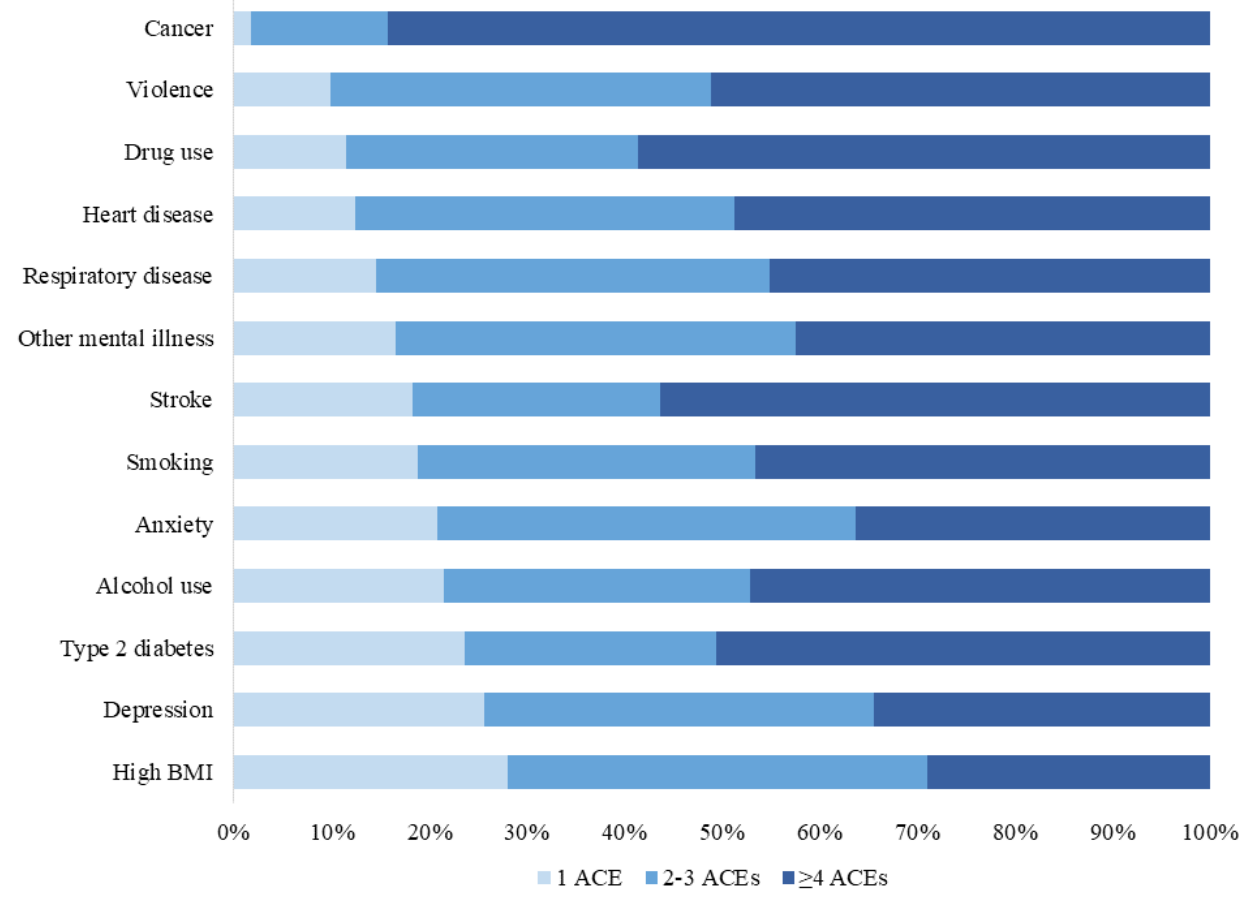

Figure 1 Proportion of ACE-attributable costs for each risk factor and cause of ill health attributed to 1, 2-3 and $\geq 4$ ACE categories. ACE, adverse childhood experience; BMI, body mass index.

Wales, ${ }^{23}$ while some outcome measures could not be matched directly to GBD categories (see online supplementary table S4). Like previous ACE studies, the retrospective, self-reported nature of questions makes findings subject to recall issues and any reluctance to report historical experiences. Further, some population groups who may be at increased exposure to ACEs (eg, those incarcerated $^{36}$ or homeless ${ }^{37}$ ) will have been under-represented and we could not account for individuals that had died prematurely through conditions related to ACEs. These biases may have led to reduced relative risks. Conversely, while ACEs made an overall significant contribution to GLMs (generalised linear models) for all outcomes, for some, RRs were not significant at all ACE levels. Further, our samples were restricted to adults aged 18-69 years, yet some conditions such as stroke occur predominantly in older age groups. Consequently sensitivity analyses were undertaken limiting DALYs to the 15-69years age group and using lower and upper CIs for RRs. While we excluded DALYs for risk factors linked to included causes of ill health in calculating our overall cost estimates, it is beyond the ability of this study to calculate the actual burden of ACEs due to multiplicative relationships. However, our estimates of the costs of ACEs are likely to be conservative. While we included many key risks for, and causes of, ill health associated with ACEs, we did not account for other associated outcomes (eg, risky sexual behaviour, suicide, crime), nor for the burden of child deaths related to ACEs. A study of child death reviews in an English locality found evidence of at least one ACE in the records of $63 \%$ of children that died over a 4 -year period and of at least four ACEs in $20 \%$ of cases. ${ }^{38}$ The lifetime cost of a child maltreatment death in the UK has been estimated at almost $£ 1$ million. ${ }^{35}$

\section{Meaning of the study}

Nearly half of all adults in England and Wales experienced some form of ACE as a child and around one in ten experienced $\geq 4$ ACEs (see online supplementary table S5). This equates to approximately 20 million adults with any ACE and four million with $\geq 4$ ACEs. Our results quantify the substantive proportion of common healthharming behaviours and long-term health conditions that are associated with ACEs, and consequently that could be avoided in future generations through offering better quality childhoods. Currently, however, an estimated 2.3 million children in England live in families with substantial complex needs and only a third of these children are receiving established support from statutory services. ${ }^{39}$ An imperative to increase expenditure on safe and nurturing childhoods is emphasised by findings that around a third of mental illness could be avoided if ACEs were either prevented or their impacts moderated through early intervention. Mental illness carries one of the highest costs to health systems in England and Wales $^{40}$ and also creates substantial pressure on educational, social and criminal justice systems. For the latter in particular, strong relationships found here between ACEs and violence are an additional concern with many types of police-recorded violence increasing in England and Wales. ${ }^{41}$ Across all measured outcomes, we identify potentially avoidable costs from ACEs equivalent to more than a quarter of the UK's annual government healthcare expenditure. $^{42}$ The potential to avoid such costs is unrealised 
while the majority of health expenditure focuses on adults who have already developed pathologies. Evidencebased mechanisms to prevent ACEs and build resilience to their long-term harms are available, offering return on investments in years rather than decades through benefits on child development, health and education. ${ }^{43-46}$ The benefits of such interventions reach across sectors, and a whole of government approach could more immediately resource interventions capable of diminishing a current annual ACE burden of almost $£ 43$ billion.

\section{Unanswered questions and future research}

As with most ACE studies our data were collected retrospectively and consequently provide no information on the current levels of ACEs experienced by children in England and Wales. Options to measure ACE prevalence now form part of the international Health Behaviour in School-aged Children Survey ${ }^{47}$ but have not yet been used in the English or Welsh survey iterations, nor are such data routinely being collected through other major schoolbased surveys in the UK. While estimates of current exposure to some ACEs are available ${ }^{39}$ routine measurement of ACEs in children is required to better understand their extent and sociodemographic and geographical distribution, as well as the impact of interventions to address them. Further, our findings identified that, despite having the lowest prevalence, the majority of costs generated by ACEs fall on those experiencing $\geq 4$ ACEs (table 2). There is an urgent need to better understand the cumulative impact of ACEs on health outcomes across the life course, integrating epidemiology with fields including epigenetics, immunology and neurology. Equally, there is a critical need for knowledge on how services can become more trauma-informed, what impact trauma-informed service delivery can have, and how services for children and families affected by child maltreatment, substance abuse, domestic violence or incarceration, for instance, can be better integrated to provide a cohesive offer. Finally, as well as the core ACE categories included here, measurements of other childhood adversities such as neglect, parental bereavement, bullying and exposure to community level violence are increasingly being incorporated into the list of potential ACEs. Public services that recognise the impact of childhood adversity on lifelong health but neglect to implement preventative measures may yet feature in future lists.

\section{Twitter Karen Hughes @keh444 and Mark A Bellis @markabellis}

Acknowledgements We would like to thank all those involved in developing and implementing the individual studies that contributed to this study, and the English and Welsh residents who participated in the surveys.

Contributors $\mathrm{MAB}$ and $\mathrm{KH}$ designed the study. MAB developed the statistical modelling, and $\mathrm{KH}, \mathrm{KF}$ and $\mathrm{CAS}$ conducted the data analyses. $\mathrm{KH}$ wrote the manuscript with contributions from MAB, KF and RK. All authors reviewed the study findings and read and approved the final version before submission.

Funding The authors have not declared a specific grant for this research from any funding agency in the public, commercial or not-for-profit sectors.

Disclaimer The corresponding author attests that all listed authors meet the authorship criteria and that no others meeting the criteria have been omitted.
Competing interests None declared.

Patient and public involvement Patients and/or the public were not involved in the design, or conduct, or reporting, or dissemination plans of this research.

Patient consent for publication Not required.

Ethics approval Ethical approval for the 2017 Welsh national sample was obtained from Bangor University's Healthcare and Medical Sciences Ethics Committee (BU230317), with ethical approval for all other studies obtained through the Liverpool John Moores University Research Ethics Panel (12/HEA/016; 13/HEA/052; 14/EHC/008; 14/EHC/0087). Additional approval for both Welsh surveys was provided by the Public Health Wales Research and Development Office.

Provenance and peer review Not commissioned; externally peer reviewed.

Data availability statement The data sets analysed in the current study are available from the corresponding author on reasonable request.

Open access This is an open access article distributed in accordance with the Creative Commons Attribution Non Commercial (CC BY-NC 4.0) license, which permits others to distribute, remix, adapt, build upon this work non-commercially, and license their derivative works on different terms, provided the original work is properly cited, appropriate credit is given, any changes made indicated, and the use is non-commercial. See: http://creativecommons.org/licenses/by-nc/4.0/.

ORCID iD

Karen Hughes http://orcid.org/0000-0001-8097-3395

\section{REFERENCES}

1 Hughes K, Bellis MA, Hardcastle KA, et al. The effect of multiple adverse childhood experiences on health: a systematic review and meta-analysis. Lancet Public Health 2017;2:e356-66.

2 Anda RF, Butchart A, Felitti VJ, et al. Building a framework for global surveillance of the public health implications of adverse childhood experiences. Am J Prev Med 2010;39:93-8.

3 Berens AE, Jensen SKG, Nelson CA. Biological embedding of childhood adversity: from physiological mechanisms to clinical implications. BMC Med 2017;15:135.

4 Teicher MH, Samson JA, Anderson CM, et al. The effects of childhood maltreatment on brain structure, function and connectivity. Nat Rev Neurosci 2016;17:652-66.

5 Oh DL, Jerman P, Silvério Marques S, et al. Systematic review of pediatric health outcomes associated with childhood adversity. BMC Pediatr 2018;18:83.

6 Jimenez ME, Wade R, Lin Y, et al. Adverse experiences in early childhood and kindergarten outcomes. Pediatrics 2016;137:e20151839.

7 Bright MA, Thompson LA. Association of adverse childhood experiences with co-occurring health conditions in early childhood. $J$ Dev Behav Pediatr 2018;39:37-45.

8 Holman DM, Ports KA, Buchanan ND, et al. The association between adverse childhood experiences and risk of cancer in adulthood: a systematic review of the literature. Pediatrics 2016;138:S81-91.

9 Norman RE, Byambaa M, De R, et al. The long-term health consequences of child physical abuse, emotional abuse, and neglect: a systematic review and meta-analysis. PLoS Med 2012;9:e1001349.

10 Peterson C, Florence C, Klevens J. The economic burden of child maltreatment in the United States, 2015. Child Abuse Negl 2018;86:178-83.

11 Fang X, Fry DA, Brown DS, et al. The burden of child maltreatment in the East Asia and Pacific region. Child Abuse Negl 2015;42:146-62.

12 Bellis MA, Hughes K, Ford K, et al. Life course health consequences and associated annual costs of adverse childhood experiences across Europe and North America: a systematic review and metaanalysis. Lancet Public Health 2019;4:e517-28.

13 Baglivio MT, Epps N, Swartz K, et al. The prevalence of adverse childhood experiences (ACE) in the lives of juvenile offenders. J Juv Justice 2014;3:12-34.

14 Metzler M, Merrick MT, Klevens J, et al. Adverse childhood experiences and life opportunities: shifting the narrative. Child Youth Serv Rev 2017;72:141-9.

15 Hardcastle K, Bellis MA, Ford K, et al. Measuring the relationships between adverse childhood experiences and educational and employment success in England and Wales: findings from a retrospective study. Public Health 2018;165:106-16.

16 Hughes K, Bellis MA, Sethi D, et al. Adverse childhood experiences, childhood relationships and associated substance use and mental health in young Europeans. Eur J Public Health 2019;29:741-7. 
17 Pachter LM, Lieberman L, Bloom SL, et al. Developing a communitywide initiative to address childhood adversity and toxic stress: a case study of the Philadelphia ACE Task force. Acad Pediatr 2017:17:S130-5.

18 Science and Technology Select Committee. Evidence-Based early years intervention, 2018. Available: https://publications.parliament. uk/pa/cm201719/cmselect/cmsctech/506/50602.htm [Accessed 30 Sep 2019].

19 Bellis MA, Hughes K, Leckenby N, et al. Measuring mortality and the burden of adult disease associated with adverse childhood experiences in England: a national survey. J Public Health 2015;37:445-54.

20 Bellis MA, Lowey H, Leckenby N, et al. Adverse childhood experiences: retrospective study to determine their impact on adult health behaviours and health outcomes in a UK population. $J$ Public Health 2014;36:81-91.

21 Ford K, Butler N, Hughes K, et al. Adverse childhood experiences in Hertfordshire, Luton and Northamptonshire. Liverpool: Centre for Public Health, Liverpool John Moores University, 2016. https:// www.researchgate.net/publication/302589403_Adverse_Childhood Experiences_ACEs_in_Hertfordshire_Luton_and_Northamptonshire

22 Bellis MA, Ashton K, Hughes K, et al. Adverse childhood experiences and their impact on health-harming behaviours in the Welsh population. Cardiff: Public Health Wales, 2016. https://www. researchgate.net/publication/290433553_Adverse_Childhood Experiences_and_their_impact_on_health-harming_behaviours_in the_Welsh_adult_population

23 Hughes K, Ford K, Davies AR, et al. Sources of resilience and their Moderating relationships with harms from adverse childhood experiences. Wrexham: Public Health Wales, 2018. https://www. researchgate.net/publication/322697404 Sources of resilience and_their_moderating_relationships_with_harms_from_adverse _ childhood_experiences_Report_1_Mental_Illness

24 Ministry of Housing, Communities \& Local Government. English indices of deprivation. Available: https://www.gov.uk/government/ collections/english-indices-of-deprivation [Accessed 17 Oct 2019].

25 Stats Wales. Welsh index of multiple deprivation. Available: https:// statswales.gov.wales/Catalogue/Community-Safety-and-SocialInclusion/Welsh-Index-of-Multiple-Deprivation [Accessed 17 Oct 2019].

26 Centers for Disease Control and Prevention. BRFSS ACE module. Available: https://www.cdc.gov/violenceprevention/ childabuseandneglect/acestudy/ace-brfss.html [Accessed $30 \mathrm{Sep}$ 2019].

27 Barendregt JJ, Veerman JL. Categorical versus continuous risk factors and the calculation of potential impact fractions. $J$ Epidemiol Community Health 2010;64:209-12.

28 Brown DW. Economic value of disability-adjusted life years lost to violence: estimates for who member states. Rev Panam Salud Publica 2008;24:203-9.

29 Pike J, Grosse SD. Friction cost estimates of productivity costs in cost-of-illness studies in comparison with human capital estimates: a review. Appl Health Econ Health Policy 2018;16:765-78.

30 Institute for Health Metrics and Evaluation. Global burden of disease 2017. Available: http://ghdx.healthdata.org/gbd-results-tool [Accessed 25 Feb 2019].

31 Office for National Statistics. Nominal regional gross value added (balanced) per head and income components. Available: https:// www.ons.gov.uk/economy/grossvalueaddedgva/datasets/nominal egionalgrossvalueaddedbalancedperheadandincomecomponents [Accessed 17 Oct 2019].
32 Office for National Statistics. Number of households by local and unitary authorities in England and Wales, and total number of households in Northern Ireland, 2004 to 2017. Available: https:// www.ons.gov.uk/peoplepopulationandcommunity/birthsdeathsandm arriages/families/adhocs/010265numberofhouseholdsbylocalandun itaryauthoritiesinenglandandwalesandtotalnumberofhouseholdsinnor thernireland2004to2017 [Accessed 11 October 2019].

33 Fang X, Zheng X, Fry DA, et al. The economic burden of violence against children in South Africa. Int J Environ Res Public Health 2017; 14:E1431.

34 Fang X, Fry DA, Ji K, et al. The burden of child maltreatment in China: a systematic review. Bull World Health Organ 2015;93:176-85.

35 Conti G, Morris S, Melnychuk M, et al. The economic costs of child maltreatment in the UK. London: NSPCC and University College London, 2017. https://learning.nspcc.org.uk/research-resources/ 2017/economic-cost-child-maltreatment/

36 Ford K, Newbury A, Barton E, et al. Understanding the prevalence of adverse childhood experiences (ACEs) in a male offender population in Wales: the prisoner ACE survey. Wrexham: Public Health Wales NHS Trust, Bangor University, 2019. https://www. bangor.ac.uk/news/documents/PHW-Prisoner-ACE-Survey-ReportE.pdf

37 Sundin EC, Baguley T. Prevalence of childhood abuse among people who are homeless in Western countries: a systematic review and meta-analysis. Soc Psychiatry Psychiatr Epidemiol 2015;50:183-94.

38 Grey HR, Ford K, Bellis MA, et al. Associations between childhood deaths and adverse childhood experiences: an audit of data from a child death overview panel. Child Abuse Negl 2019;90:22-31.

39 Children's Commissioner for England. Childhood vulnerability in numbers. London: Children's Commissioner, 2019. https://www.chil drenscommissioner.gov.uk/publication/childhood-vulnerability-inengland-2019/

40 Mental Health Taskforce to the NHS in England. The five year forward view for mental health. NHS England, 2016. https://www.england. nhs.uk/wp-content/uploads/2016/02/Mental-Health-Taskforce-FYFVfinal.pdf

41 Office for National Statistics. Crime in England and Wales: year ending June 2019. Available: https://www.ons.gov.uk/peoplepo pulationandcommunity/crimeandjustice/bulletins/crimeinenglandan dwales/yearendingjune2019\#rise-in-offences-involving-knives-orsharp-instruments-and-firearms-offences [Accessed 21 Oct 2019].

42 Office for National Statistics. Healthcare expenditure, UK health accounts: 2017. Available: https://www.ons.gov.uk/peoplepopula tionandcommunity/healthandsocialcare/healthcaresystem/bulletins/ ukhealthaccounts/2017 [Accessed 14 October 2019].

43 Britto PR, Lye SJ, Proulx K, et al. Nurturing care: promoting early childhood development. Lancet 2017;389:91-102.

44 Gardner F, Leijten P, Mann J, et al. Could scale-up of parenting programmes improve child disruptive behaviour and reduce social inequalities? using individual participant data meta-analysis to establish for whom programmes are effective and cost-effective. Public Health Res 2017;5:1-144.

45 Ramon I, Chattopadhyay SK, Barnett WS, et al. Early childhood education to promote health equity: a community guide economic review. J Public Health Manag Pract 2018;24:e8-15.

46 Purewal Boparai SK, Au V, Koita K, et al. Ameliorating the biological impacts of childhood adversity: a review of intervention programs. Child Abuse Negl 2018;81:82-105.

47 Health behaviour in school-aged children: World Health organization collaborative cross national survey. Available: http://www.hbsc.org/ index.aspx [Accessed 14 Oct 2019]. 